\title{
Metformin inhibits endothelial progenitor cell migration by decreasing matrix metalloproteinases, MMP-2 and MMP-9, via the AMPK/mTOR/autophagy pathway
}

\author{
WEN-DONG LI* ${ }^{*}$ NENG-PING LI*, DAN-DAN SONG, JIAN-JIE RONG, AI-MIN QIAN and XIAO-QIANG LI \\ Department of Vascular Surgery, The Second Affiliated Hospital of Soochow University, \\ Suzhou, Jiangsu 215000, P.R. China
}

Received October 25, 2016; Accepted March 15, 2017

DOI: $10.3892 /$ ijmm.2017.2929

\begin{abstract}
The aim of the present study was to investigate the effect of metformin on endothelial progenitor cell (EPC) migration and to explore the possible mechanisms. EPCs were treated with metformin, and the migration of EPCs was evaluated by wound healing and Matrigel invasion assays. We also examined the expression levels of of MMP-2 and MMP-9 in EPCs with or without metformin treatment via RT-PCR and western blot analysis, and activities of MMP-2 and MMP-9 in EPCs under different conditions was examined by zymography. Moreover, we also assessed the AMPK/mTOR/autophagy pathway to explore the possible mechanisms. Metformin treatment significantly downregulated matrix metalloproteinase-2 (MMP-2) and MMP-9 expression, and subsequently decreased the migration of EPCs. Increased levels of phosphorylated (p)-AMPK and LC3II expression, as well as decreased levels of p-mTOR and p62 contributed to this phenomenon. The AMPK inhibitor compound $\mathrm{C}$ reversed the effect exerted by metformin. In conclusion, our results showed that metformin inhibited the migration of EPCs by decreasing MMP-2 and MMP-9. The AMPK/mTOR/autophagy pathway was demonstrated to be involved in the regulatory mechanisms.
\end{abstract}

\section{Introduction}

Endothelial progenitor cells (EPCs), which were firstly identified in adult human peripheral blood (PB) in 1997 (1), exhibit the capacity for endothelial differentiation (2) and angiogenic growth factor and cytokine secretion $(3,4)$. As a novel thera-

Correspondence to: Professor Xiao-Qiang Li, Department of Vascular Surgery, The Second Affiliated Hospital of Soochow University, 1055 Sanxiang Road, Suzhou, Jiangsu 215000, P.R. China E-mail: vasculars@126.com; flytsg@126.com

${ }^{*}$ Contributed equally

Key words: metformin, endothelial progenitor cells, migration, autophagy, adenosine monophosphate activated protein kinase peutic target for vascular diseases (5), they can incorporate into ischemic tissue and play an important role in vasculogenesis for physiological or pathological neovascularization (6-9). In addition, EPCs have been reported to play an important role in thrombosis resolution (10-13).

However, EPCs are present in very low numbers (0.1-0.01\% of mononuclear cells). Moreover, some risk factors of vascular diseases, for example age, smoking, coronary artery disease (CAD), atherosclerosis and diabetes mellitus (DM) (14-16), may reduce the number of EPCs in PB (10). EPCs from CAD and DM patients exhibit decreased migration as well as mobilization capacity (16-18). Migration is essential for EPCs to mobilize to the sites of ischemic tissue. These factors decrease the numbers of EPCs in circulation and subsequently impair the capacity of vascular endothelium repair. Thus, how to promote EPCs to mobilize from the bone marrow (BM) niche and migrate into special sites remains a current issue.

Metformin, an activator of AMPK and an inhibitor of mTOR (19), is widely endorsed as initial therapy for type 2 diabetes because of its low cost, safety profile, and potential cardiovascular benefits (20). It has been demonstrated that metformin improves endothelial function and enhances the neovascularization of EPCs $(21,22)$. At the same time, in our previous study, metformin promoted EPC differentiation (23). But, the exact effect of metformin on circulating EPC migration is still poorly understood. In this study, we investigated the effect of metformin on the migration of EPCs and explored the possible mechanisms.

\section{Materials and methods}

Antibodies and reagents. Antibodies for phospho(p)-AMPK (\#4185), AMPK (\#2532), p-Akt (\#9018), Akt (\#9272), mTOR (\#2972), LC3B (\#2775) were from Cell Signaling Technology (Danvers, MA, USA). Antibodies for p62 (ab56416), matrix metalloproteinase-2 (MMP-2; ab92536) and MMP-9 (ab76003) were obtained from Abcam, Inc. (Cambridge, MA, USA). Antibody for p-mTOR (sc-293132) was purchased from Santa Cruz Biotechnology, Inc. (Santa Cruz, CA, USA). Metformin, AMPK inhibitor compound C (CC), mitomycin $C$, and the antibody for $\beta$-actin (A3854) were purchased from Sigma-Aldrich (St. Louis, MO, USA). 
Isolation and characterization of human EPCs. Mononuclear cells were isolated from PB using the Histopaque density centrifugation method. Fresh blood (50-100 ml) was collected from volunteer donors by venipuncture and anticoagulated with heparin. The Institutional Review Board at the Second Affiliated Hospital of Soochow University approved all protocols, and informed consent was obtained from all adult donors.

Human mononuclear cells (MNCs) were isolated as previously described (24). Briefly, the anticoagulated blood was diluted 1:1 with phosphate-buffered saline (PBS). Mononuclear cells, isolated by density gradient centrifugation using Lymphocyte Separation Medium-LSM ${ }^{\mathrm{TM}}$ (MP Biomedicals, Santa Ana, CA, USA), were seeded onto collagen I-coated plates (Invitrogen, Carlsbad, CA, USA) at a density of $2.5 \times 10^{6}$ cells $/ \mathrm{cm}^{2}$ and cultured with Endothelial Cell Growth Medium-2 (EGM-2MV; Lonza, Walkersville, MD, USA) supplemented with $10 \%$ fetal bovine serum (FBS; Gibco, Carlsbad, CA, USA) and maintained in a $37^{\circ} \mathrm{C} / 5 \% \mathrm{CO}_{2}$ incubator. Medium was changed daily for 7 days and then every other day until the first passage. Cells within 10 passages were used for the following experiments.

EPC surface molecule analysis. EPC surface molecule analysis was performed as previous described by flow cytometry $(25,26)$. Cells were detached with EDTA and labeled for $20 \mathrm{~min}$ at $4^{\circ} \mathrm{C}$ at manufacturer-recommended concentrations with fluorescent antibodies, including anti-VEGFR-2-PE (\#560872), anti-CD45-FITC (\#560976), anti-CD14-FITC (\#561710), anti-CD133-PE (\#130-080-801), and anti-CD31-PE (\#566125) and anti-CD34-FITC (\#560942). Fluorescent isotype-matched antibodies were used as negative controls. All antibodies were obtained from Becton-Dickinson (Franklin Lakes, NJ, USA), except anti-CD133-PE (Miltenyi Biotec, Auburn, CA, USA). Cells were washed, paraformaldehyde-fixed (Tosoumis, Rockville, MD, USA), and analyzed on a FACSCalibur Instrument (Becton-Dickinson) with 10,000 events stored. Other commonly accepted criteria for identifying EPCs, for example, uptake of DiI-acLDL and FITC-UEA-I binding, were also performed.

To evaluate the effect of metformin, identified EPCs were incubated with $10 \mathrm{mM}$ metformin for $24 \mathrm{~h}$. In the setting of mechanism verification, AMPK inhibitor compound $\mathrm{C}$ was added at a concentration of $10 \mu \mathrm{M}$.

Wound healing migration assay. A wound healing migration assay with EPCs was performed following previously

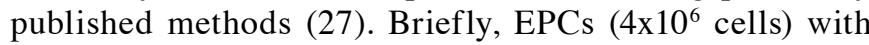
$10 \mathrm{mM}$ metformin were resuspended and seeded into a 6-well plate, and grew until $\sim 100 \%$ confluence. Cells were treated with $10 \mu \mathrm{g} / \mathrm{ml}$ mitomycin $\mathrm{C}$ for $3 \mathrm{~h}$ to block cell proliferation. A linear scratch was made by using a $10-\mu 1$ pipette tip. After washing with PBS twice, the cells were incubated with serum free EGM-2MV medium for specific times. Images were taken at 0 and $24 \mathrm{~h}$ at $\times 40$ magnification and the wound size was measured in 3 wells/group.

Matrigel invasion assay. EPC migration assay was performed in a Transwell system as described previously (28). A Transwell chamber was used (8- $\mu \mathrm{m}, 24$-well plate). In the invasion assay, the insert membranes were coated with diluted Matrigel. EPCs
( $2 \times 10^{5}$ cells) were resuspended in $200 \mu 1$ serum-free EGM-2MV medium and seeded into the upper chamber after treatment with $10 \mu \mathrm{g} / \mathrm{ml}$ mitomycin $\mathrm{C}$ for $3 \mathrm{~h}$. The lower chamber was filled with EGM-2MV medium supplemented with $10 \% \mathrm{FBS}$, vehicle control or $10 \mathrm{mM}$ metformin. After incubation at $37^{\circ} \mathrm{C}$ in $5 \% \mathrm{CO}_{2}$ for $24 \mathrm{~h}$, the cells were stained with crystal violet and the cell number in each well was counted in 3 randomly picked fields (magnification, x200) under a light microscope. All the experiments were performed in triplicate.

Real-time reverse transcription polymerase chain reaction $(R T-P C R)$. After EPCs were treated as described above, total cellular RNA was extracted using TRIzol reagent (Invitrogen). Real-time RT-PCR was carried out using a SYBR ${ }^{\circledR}$-Green qPCR Mix (Thermo Scientific, MBI Fermentas, Waltham, MA, USA) and a Roche LightCycler 480 (Roche, Basel, Switzerland). Expression of the glyceraldehyde 3-phosphate dehydrogenase (GAPDH) gene was assessed simultaneously in all samples as an internal control. Relative gene expression was determined by the $2^{-\Delta \Delta \mathrm{Cq}}$ method (29). The following primers were used: MMP-2 sense, 5'-GGT TCC CCT GTT CAC TCT ACT TAG C-3' and antisense, 5'-CGG CTT GGT TTT CCT CCA T-3'; MMP-9 sense, 5'-CCC GGA GTG AGT TGA ACC A-3' and antisense, 5'-AGG GCA CTG CAG GAT GTC A-3'; GAPDH sense, 5'-GGT GGT CTC CTC TGA CTT CAA CA-3' and antisense, 5'-GTG GTC GTT GAG GGC AAT G-3'.

Western blot analysis. EPCs $\left(1 \times 10^{6}\right.$ cells $)$ were lysed in RIPA buffer, followed by high-speed centrifugation and bicinchoninic acid quantification. Cellular proteins were separated by sodium dodecyl sulfate-polyacrylamide gel electrophoresis (SDS-PAGE) and transferred onto polyvinylidene difluoride membranes. After blocking with 5\% non-fat milk Tris-buffered saline-Tween-20 (TBS-T), the membranes were incubated with primary antibodies against AMPK, p-AMPK, Akt, p-Akt, p-mTOR, mTOR, MMP-2, MMP-9, LC-3B and p62. Appropriate horseradish peroxidase-conjugated secondary antibodies were applied. $\beta$-actin (Sigma-Aldrich) was used as the loading control. The protein bands were detected with Super Signal West PicoChemiluminescent Substrate (Pierce, Rockford, IL, USA) on X-ray film (Kodak, Tokyo, Japan).

SDS-PAGE gelatin zymography. The activities of MMP-2 and MMP-9 were determined by gelatin zymography as previously described (30,31). Ten micrograms of each sample was loaded onto a $8 \%$ SDS-polyacrylamide gel containing $1 \mathrm{mg} / \mathrm{ml}$ gelatin, electrophoresed, renatured, and developed. Gels were stained with $0.25 \%$ Coomassie Brilliant Blue R-250 and destained in the same solution without dye. Gelatinase activity was visualized as clear bands against the blue-stained gelatin background and analyzed in a computer system. Three individual experiments were conducted with independent protein samples.

Statistical analyses. All statistical analyses were carried out using SPSS v21 (SPSS, Inc., Chicago, IL, USA). Data are presented as mean \pm standard deviation (SD). Student's t-test or one way ANOVA was utilized to examine differences between two groups or multiple group comparison. $\mathrm{P}<0.05$ was considered as statistically significant. 
A DiI acLDL

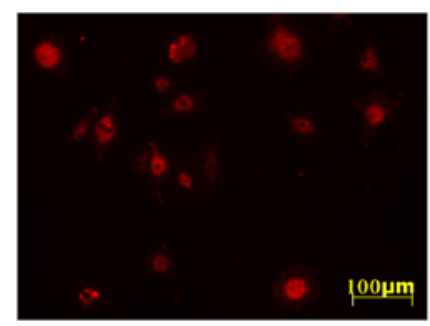

B

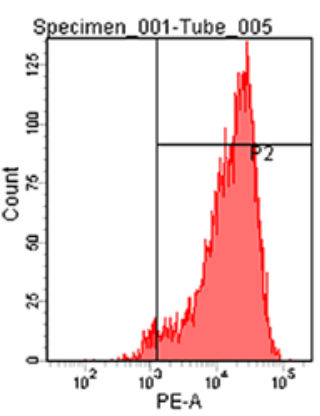

CD31

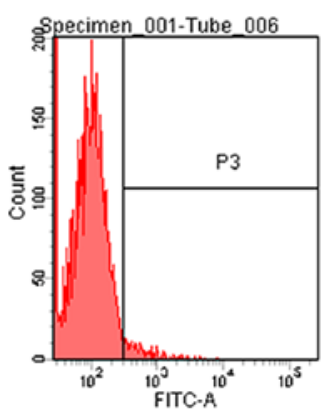

CD34
FITC-UEA-I
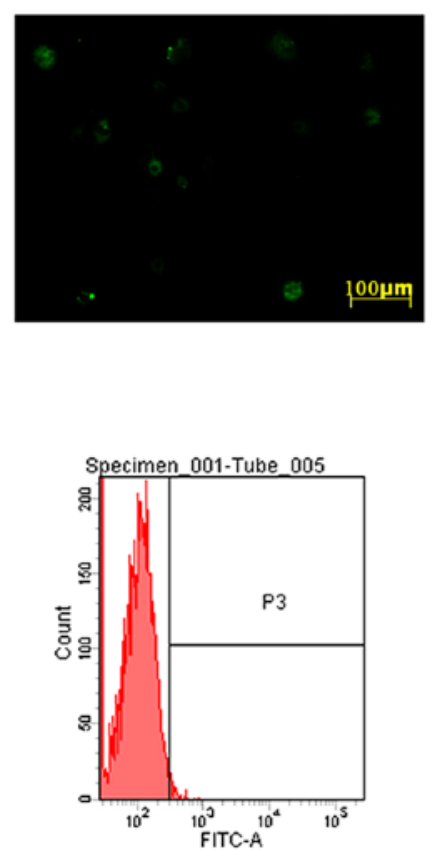

CD14

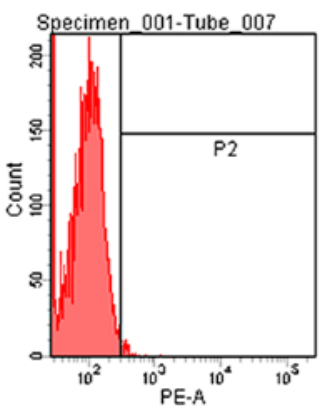

CD133
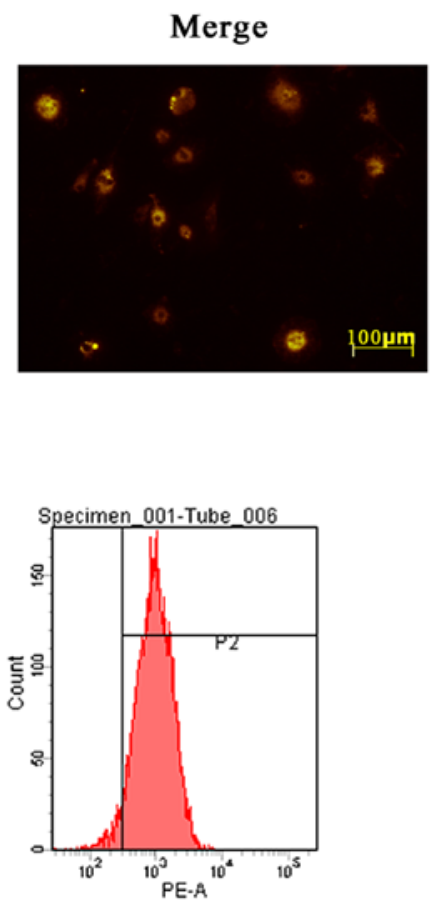

VEGFR-2

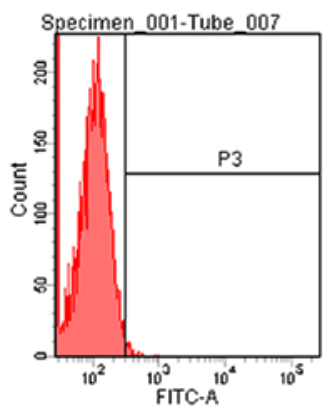

CD45

Figure 1. Characterization of endothelial progenitor cells (EPCs). (A) Dil-Ac-LDL uptake and FITC-UEA-I binding of isolated EPCs were determined by fluorescence microscopy. (B) Flow cytometric analysis of EPCs. Cells were labelled with antibodies to CD31, CD14, VEGFR-2, CD34, CD133 and CD45. Histograms represent cell number (y-axis) vs. fluorescence intensity (x-axis, log scale). Cells $(10,000)$ were acquired and gates were set on living cells.

\section{Results}

$E P C$ characterization. Isolated MNCs were cultured in EGM-2MV medium supplemented with $10 \%$ FBS and growth factors to be induced into EPCs. EPCs were identified by morphology, fluorescence double-staining and flow cytometry. Most adherent cells were double stained by DiI-AcLDL and FITC-UEA-I (Fig. 1A). The flow cytometric analysis matched with the previously described EPC phenotype $(25,26)$ (Fig. 1B). The results of identification of these cells were consistent with the characterization of late-outgrowth EPCs.

Metformin attenuates EPC migration. Wound healing migration and Matrigel invasion assays were employed. The results showed that metformin treatment significantly decreased EPC migration (Fig. 2).
Metformin regulates EPC migration by influencing MMP-2 and MMP-9. Moreover, we examined the expression levels of of MMP-2 and MMP-9 in EPCs with or without metformin treatment via RT-PCR and western blot analysis. The results revealed decreased expression of MMP-2 and MMP-9 in EPCs treated with metformin (Fig. 3A and B), indicating that a decreased activity of gelatinase and fibrinolysis, may contribute to this phenomenon.

The expression of MMP-2 and MMP-9 in EPCs at different conditions was also examined by zymography. Three bands were found in the gel, representing pro-MMP-9, active MMP-9 and active MMP-2. The expression levels of both MMP-2 and MMP-9 were significantly decreased in the EPCs after incubation with metformin (Fig. 3C).

Metformin regulates migration via the AMPK/mTOR/autophagy pathway. After metformin treatment, an increased level 
A

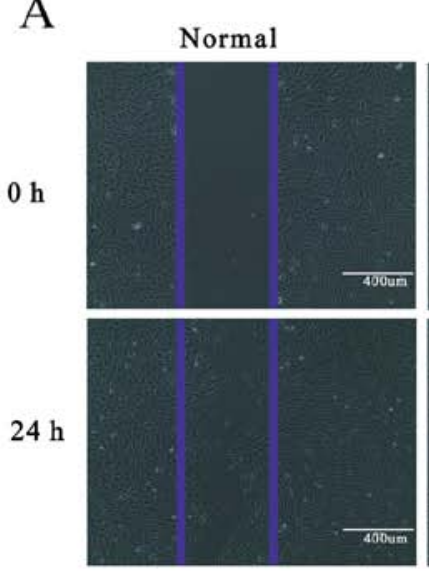

B

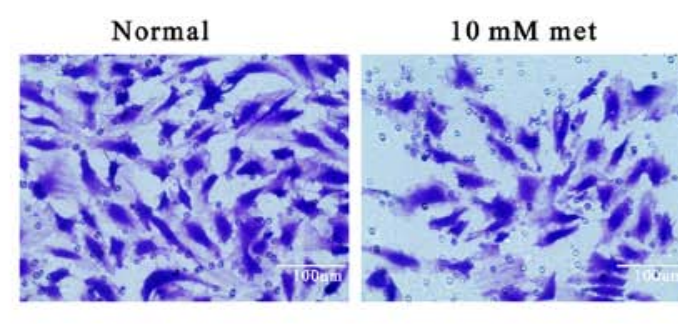

$10 \mathrm{mM}$ met+

$10 \mathrm{mM} \mathrm{met}$
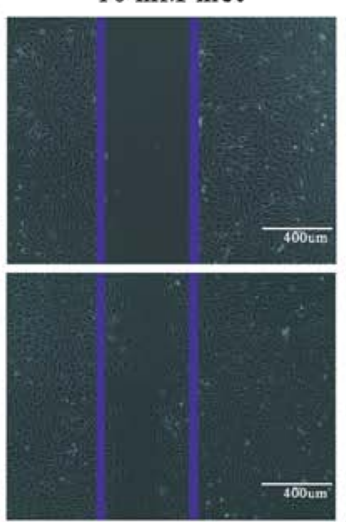

$00 \mathrm{um}$

政

\begin{abstract}
100n neat
\end{abstract} mitomycin c

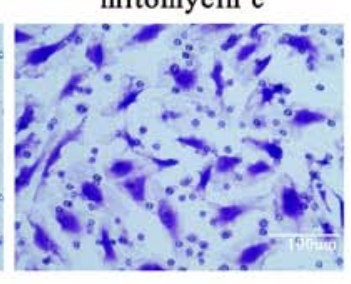

mitomycin c
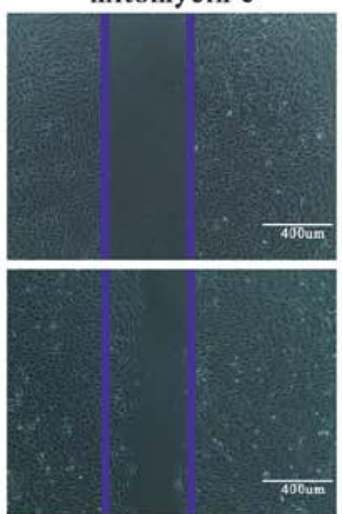
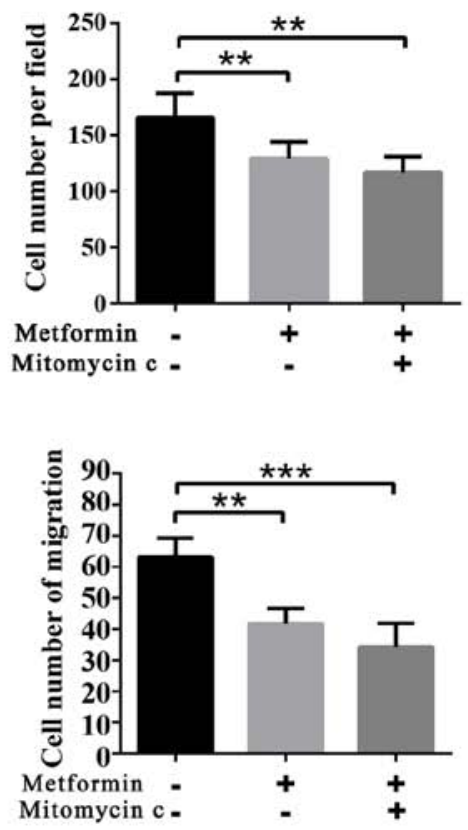

Figure 2. Effect of metformin on endothelial progenitor cell (EPC) migration. Metformin significantly decreases EPC migration. (A) Wound healing assay. Representative images of migrated EPCs in normal, metformin (met) and metformin combined with mitomycin C (met + mitomycin C) groups (magnification, x40). Wound closure was monitored by microscopy at $24 \mathrm{~h}$. (B) Transwell assay. Representative images of migrated EPCs in normal, met and met + mitomycin $\mathrm{C}$ groups (magnification, $\mathrm{x} 200$ ). Cell migration was monitored by microscopy at $24 \mathrm{~h}$ following the cell inoculation in the chamber. ${ }^{* *} \mathrm{P}<0.01,{ }^{* * * *} \mathrm{P}<0.001$ when comparison was performed between groups.

A

The mRNA expression of MMP-2 and MMP-9

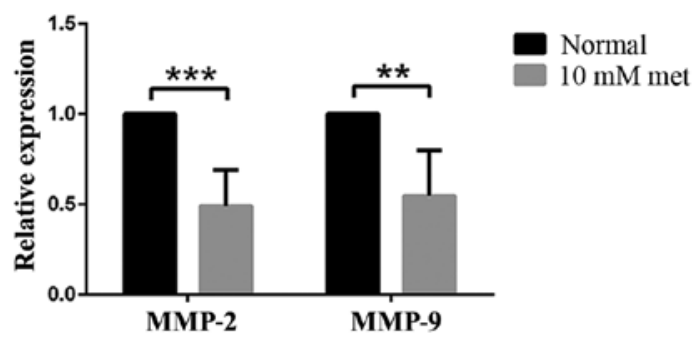

B
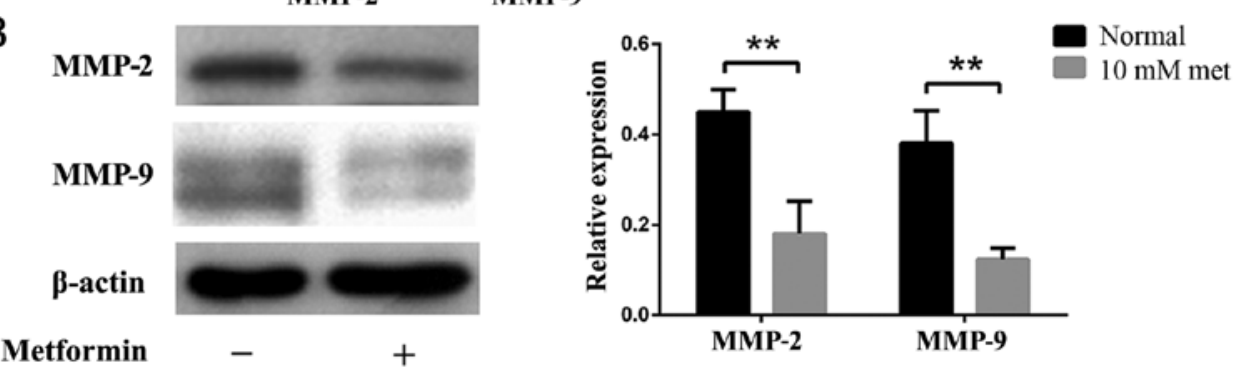

$\mathrm{C}$
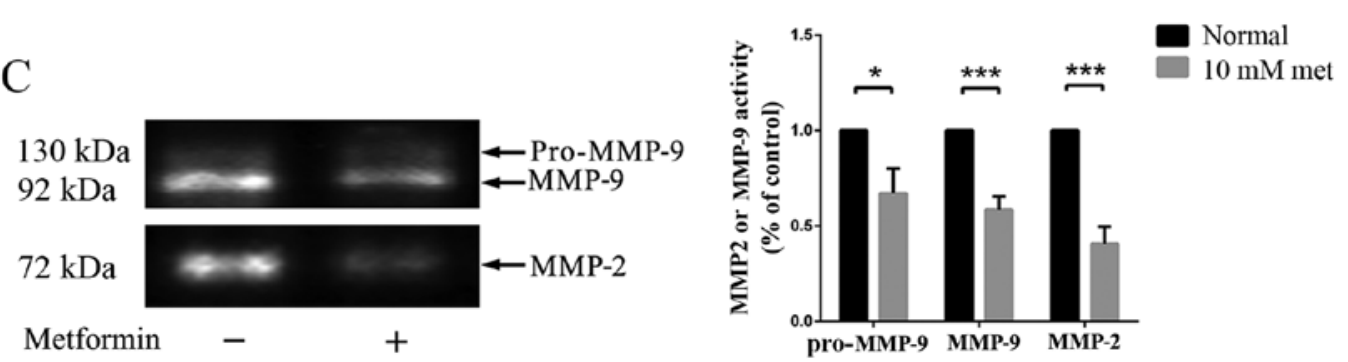

Figure 3. Metformin regulates endothelial progenitor cells (EPCs) via matrix metalloproteinase-2 (MMP-2) and MMP-9. (A) Quantitative polymerase chain reaction analyses of the expression of MMP-2 and MMP-9. (B) Western blot analyses of MMP-2 and MMP-9. (C) Gelatin zymogram of active MMP-2 and MMP-9. ${ }^{*} \mathrm{P}<0.05,{ }^{* *} \mathrm{P}<0.01,{ }^{* * *} \mathrm{P}<0.001$ when comparison was performed between groups. 

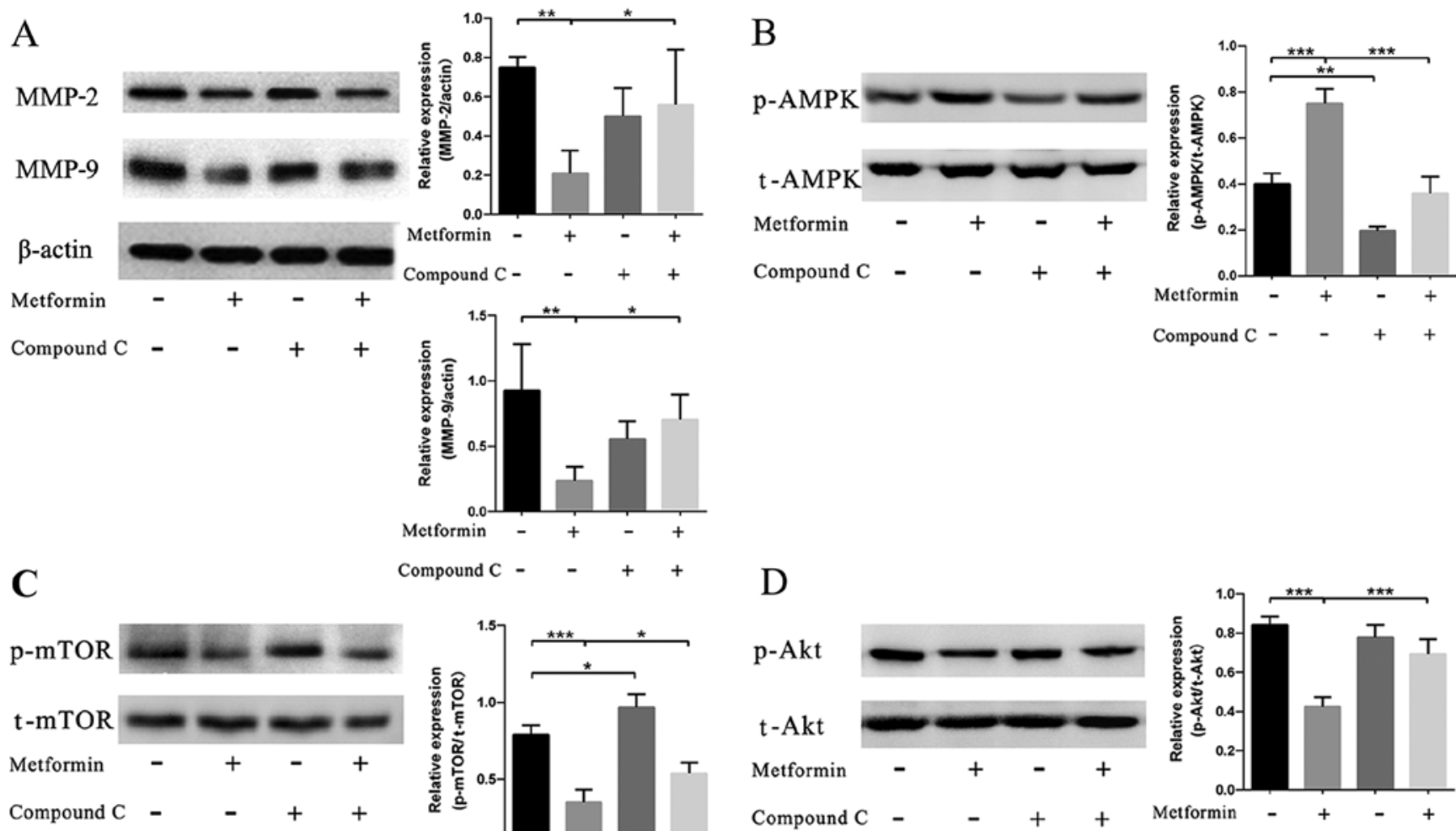

$\mathrm{D}$
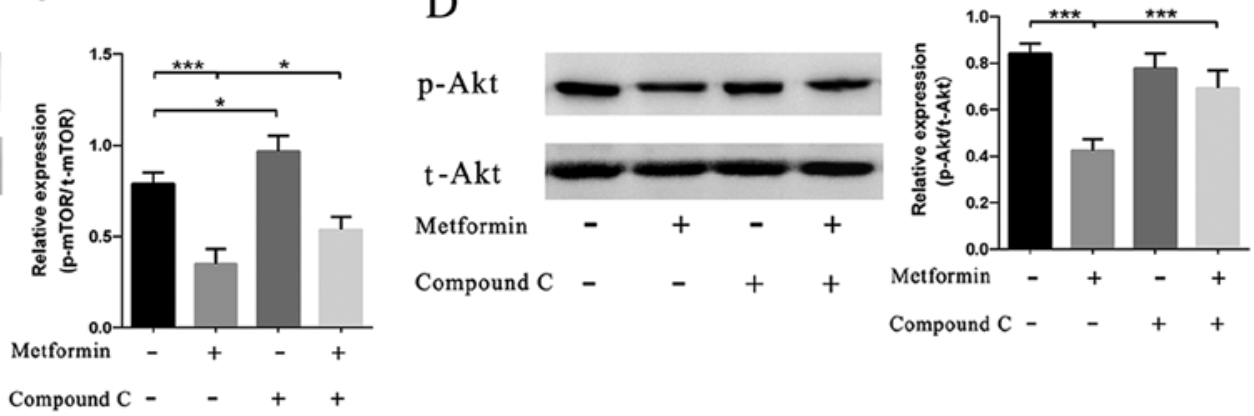

\section{$\mathrm{E}$}
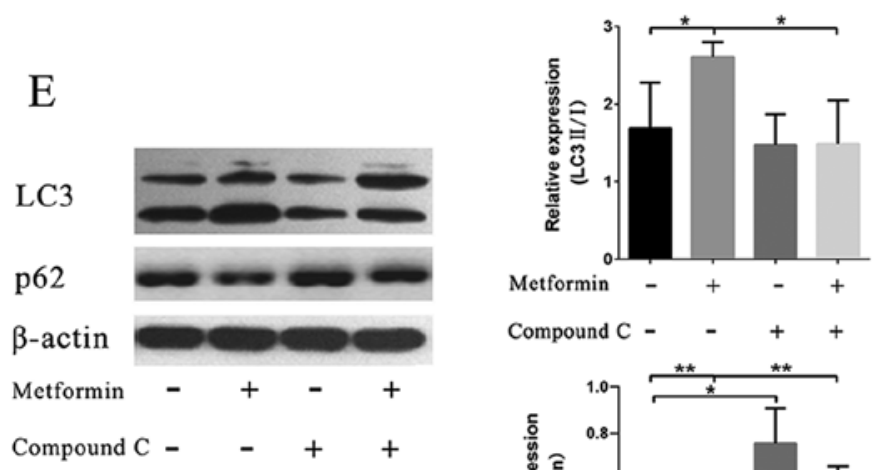

$\mathrm{F}$

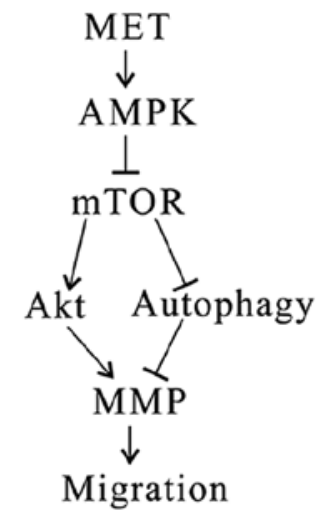

Figure 4. Metformin regulates endothelial progenitor cell (EPC) migration via the AMPK/mTOR/autophagy pathway. (A) Western blot analysis of matrix metalloproteinase-2 (MMP-2) and MMP-9 expression after $10 \mathrm{mM}$ metformin and/or $10 \mu \mathrm{M}$ AMPK inhibitor compound C treatment $(\mathrm{n}=3)$. (B-D) Western blot analysis of p-AMPK/t-AMPK, p-mTOR/t-mTOR and p-Akt/t-Akt expression respectively after $10 \mathrm{mM}$ metformin and/or $10 \mu \mathrm{M}$ AMPK inhibitor Compound C treatment (n=3). (E) Western blot analysis of LC3 and p62 expression after $10 \mathrm{mM}$ metformin and/or $10 \mu \mathrm{M}$ AMPK inhibitor Compound C treatment (n=3). (F) A proposed model of the regulation of EPC migration by metformin. ${ }^{*} \mathrm{P}<0.05,{ }^{* *} \mathrm{P}<0.01,{ }^{* * *} \mathrm{P}<0.001$.

in AMPK phosphorylation was observed (Fig. 4B), whereas the addition of AMPK inhibitor CC into the system reversed the effect of metformin. Correspondingly, MMP-2 and MMP-9 exhibited reversed changes compared with the levels of AMPK phosphorylation (Fig. 4A). Moreover, we also found decreased levels of mTOR and Akt phosphorylation (Fig. 4C and D). Furthermore, the expression of autophagy components in the EPCs was tested. An increased level of LC3B and a decreased level of p62 showed that the autophagy pathway was involved in the effect of metformin (Fig. 4E).

\section{Discussion}

EPCs, as promising therapeutic targets for vascular diseases, have been verified to improve vascular function in substantial animal and preliminary human studies $(32,33)$. Migration is 
essential for EPCs to mobilize to the sites of ischemic tissue. For example, in mice, EPCs were increased $24 \mathrm{~h}$ after DVT induction, peaking $48 \mathrm{~h}$ thereafter (12). However, the number of EPCs in DM patients was decreased, which may result from attenuated migration as well as mobilization capacity $(34,35)$. Metformin is widely endorsed as initial therapy for type 2 diabetes. In a study by Chen et al, metformin enhanced the number of circulating EPCs (36). Yet, in another study, Esposito et al (37) found no effects on the number of circulating EPCs when newly diagnosed type 2 diabetes patients were treated with metformin. Thus, the exact role of metformin on EPC migration has not been fully elaborated. In addition, there are no studies in vitro to explore the effect of metformin on EPC migration. Thus, in the present study, we aimed to investigate the effect of metformin on the migration of EPCs and explore the possible mechanisms. We found that metformin treatment attenuated EPC migration via regulating the expression of MMP-2 and MMP-9. In addition, the AMPK/mTOR/autophagy pathway was found to be involved in the effect of metformin.

It has been demonstrated that metformin is an agonist of AMPK (19), which is a member of a metabolite-sensing protein kinase family and has the capacity for the regulation of cell differentiation and migration $(38,39)$. Augmented AMPK activity inhibits cell migration (39). This may be related to the inhibition of MMPs regulated by AMPK $(40,41)$. MMPs are reported to play an important role in extracellular matrix degradation thereby facilitating the migration of leukocytes, monocytes and other types of cells in the setting of vascular diseases (42). In previous studies, it was found that metformin could regulate endothelial cell and tumor cell migration by inhibiting MMP expression. For example, metformin inhibited the migration by attenuating the expression of MMP-2 and MMP-9 in human umbilical vein endothelial cells partially through an AMPK-dependent pathway (43). Hwang et al (44) found that metformin blocked the migration and invasion of tumor cells by inhibition of MMP-9 activation. Fang et al (45) also reported that metformin reduced A498 cell migration and invasion in vitro by decreasing MMP-2. In the present study, we found that metformin inhibited EPC migration by reducing the expression and impairing the activity of MMP-2 and MMP-9, which was consistent with previous studies in other cells. We also detected the expression of AMPK, mTOR as well as Akt and found that metformin promoted AMPK phosphorylation but attenuated mTOR and Akt phosphorylation. The latter two protein kinases are involved in migration and MMP expression $(46,47)$. Meanwhile, these changes in protein kinases could result in an increased level of autophagy (Fig. 4F).

Metformin could induce autophagy by simultaneously activating AMPK and inhibiting mTORC1 in both AMPK-independent and AMPK-dependent approaches $(48,49)$. According to previous research, autophagy plays an important role in cell migration regulation but in a controversial manner. On the one hand, autophagy enhances production of various cytokines and thereby facilitates migration and invasion of lung cancer cells (50). However, on the other hand, autophagy inhibits cell migration and invasion by slowing down the lysosomal degradation of certain molecules or proteinases, such as MMPs and integrins, which are critical for cell migration $(28,51)$. In our previous study (28), we found that the different roles of autophagy in regulating cell migration may be associated with the fundamental level of autophagy and the extent of autophagy regulation.

There are a few limitations in the present study. First, we only collected EPCs from normal healthy subjects to examine the effect of metformin. The effect of metformin on the EPCs derived from patients with DM or CAD has not yet been examined. Second, the role of metformin in EPC migration under hyperglycemia should be performed in the future. Appropriate animal model studies should also be carried out to verify the functional change of EPCs in vivo. Therefore, further studies are needed to address these issues.

In conclusion, we here showed that metformin treatment regulated the migration of EPCs. The mechanisms may be associated with the AMPK/mTOR/autophagy-related pathway. The latter attenuates the expression of MMP-2 and MMP-9 (Fig. 4F).

\section{Acknowledgements}

This study was supported by grants from the Scientific and Technological Research Projects of Jiangsu Province (no. BL2014043), Graduate Research and Innovation Program in Colleges and Universities of Jiangsu Province (no. KYLX15_1202).

\section{References}

1. Asahara T, Murohara T, Sullivan A, Silver M, van der Zee R, Li T, Witzenbichler B, Schatteman G and Isner JM: Isolation of putative progenitor endothelial cells for angiogenesis. Science 275: 964-967, 1997.

2. Peichev M, Naiyer AJ, Pereira D, Zhu Z, Lane WJ, Williams M, Oz MC, Hicklin DJ, Witte L, Moore MA, et al: Expression of VEGFR-2 and AC133 by circulating human CD34(+) cells identifies a population of functional endothelial precursors. Blood 95: 952-958, 2000.

3. Urbich C, Aicher A, Heeschen C, Dernbach E, Hofmann WK, Zeiher AM and Dimmeler S: Soluble factors released by endothelial progenitor cells promote migration of endothelial cells and cardiac resident progenitor cells. J Mol Cell Cardiol 39: 733-742, 2005 .

4. Kamihata H, Matsubara H, Nishiue T, Fujiyama S, Tsutsumi Y, Ozono R, Masaki H, Mori Y, Iba O, Tateishi E, et al: Implantation of bone marrow mononuclear cells into ischemic myocardium enhances collateral perfusion and regional function via side supply of angioblasts, angiogenic ligands, and cytokines. Circulation 104: 1046-1052, 2001.

5. Asahara T, Kawamoto A and Masuda $\mathrm{H}$ : Concise review: Circulating endothelial progenitor cells for vascular medicine. Stem Cells 29: 1650-1655, 2011.

6. Shi Q, Rafii S, Wu MH, Wijelath ES, Yu C, Ishida A, Fujita Y, Kothari S, Mohle R, Sauvage LR, et al: Evidence for circulating bone marrow-derived endothelial cells. Blood 92: 362-367, 1998.

7. Asahara T, Masuda H, Takahashi T, Kalka C, Pastore C, Silver M, Kearne M, Magner M and Isner JM: Bone marrow origin of endothelial progenitor cells responsible for postnatal vasculogenesis in physiological and pathological neovascularization. Circ Res 85: 221-228, 1999.

8. Takahashi T, Kalka C, Masuda H, Chen D, Silver M, Kearney M, Magner M, Isner JM and Asahara T: Ischemia-and cytokine-induced mobilization of bone marrow-derived endothelial progenitor cells for neovascularization. Nat Med 5: 434-438, 1999.

9. Asahara T, Takahashi T, Masuda H, Kalka C, Chen D, Iwaguro H, Inai Y, Silver M and Isner JM: VEGF contributes to postnatal neovascularization by mobilizing bone marrow-derived endothelial progenitor cells. EMBO J 18: 3964-3972, 1999.

10. Li WD and Li XQ: Endothelial progenitor cells accelerate the resolution of deep vein thrombosis. Vascul Pharmacol 83: 10-16, 2016.

11. Wang W, Li C, Li W, Kong L, Qian A, Hu N, Meng Q and Li X: MiR-150 enhances the motility of EPCs in vitro and promotes EPCs homing and thrombus resolving in vivo. Thromb Res 133: 590-598, 2014. 
12. Alessio AM, Beltrame MP, Nascimento MC, Vicente CP de Godoy JA, Silva JC, Bittar LF, Lorand-Metze I, de Paula EV and Annichino-Bizzacchi JM: Circulating progenitor and mature endothelial cells in deep vein thrombosis. Int J Med Sci 10: $1746-1754,2013$.

13. Nuzzolo ER, Iachininoto MG and Teofili L: Endothelial progenitor cells and thrombosis. Thromb Res 129: 309-313, 2012.

14. Ingram DA, Lien IZ, Mead LE, Estes M, Prater DN, DerrYellin E, DiMeglio LA and Haneline LS: In vitro hyperglycemia or a diabetic intrauterine environment reduces neonatal endothelial colony-forming cell numbers and function. Diabetes 57: 724-731, 2008

15. Michaud SE, Dussault S, Haddad P, Groleau J and Rivard A: Circulating endothelial progenitor cells from healthy smokers exhibit impaired functional activities. Atherosclerosis 187: 423-432, 2006.

16. Vasa M, Fichtlscherer S, Aicher A, Adler K, Urbich C, Martin H, Zeiher AM and Dimmeler S: Number and migratory activity of circulating endothelial progenitor cells inversely correlate with risk factors for coronary artery disease. Circ Res 89: E1-E7, 2001.

17. Menegazzo L, Albiero M, Avogaro A and Fadini GP: Endothelial progenitor cells in diabetes mellitus. Biofactors 38: 194-202, 2012.

18. Fadini GP, Miorin M, Facco M, Bonamico S, Baesso I, Grego F, Menegolo M, de Kreutzenberg SV, Tiengo A, Agostini C, et al: Circulating endothelial progenitor cells are reduced in peripheral vascular complications of type 2 diabetes mellitus. J Am Coll Cardiol 45: 1449-1457, 2005

19. Zhou G, Myers R, Li Y, Chen Y, Shen X, Fenyk-Melody J, Wu M, Ventre J, Doebber T, Fujii N, et al: Role of AMP-activated protein kinase in mechanism of metformin action. J Clin Invest 108: $1167-1174,2001$.

20. Inzucchi SE, Lipska KJ, Mayo H, Bailey CJ and McGuire DK: Metformin in patients with type 2 diabetes and kidney disease: A systematic review. JAMA 312: 2668-2675, 2014.

21. Mather KJ, Verma S and Anderson TJ: Improved endothelial function with metformin in type 2 diabetes mellitus. J Am Coll Cardiol 37: 1344-1350, 2001

22. Desouza CV: Does drug therapy reverse endothelial progenitor cell dysfunction in diabetes? J Diabetes Complications 27 519-525, 2013

23. Li WD, Du XL, Qian AM, Hu N, Kong LS, Wei S, Li CL and Li XQ: Metformin regulates differentiation of bone marrow-derived endothelial progenitor cells via multiple mechanisms. Biochem Biophys Res Commun 465: 803-809, 2015

24. Ingram DA, Mead LE, Tanaka H, Meade V, Fenoglio A Mortell K, Pollok K, Ferkowicz MJ, Gilley D and Yoder MC: Identification of a novel hierarchy of endothelial progenitor cells using human peripheral and umbilical cord blood. Blood 104 2752-2760, 2004.

25. Rehman J, Li J, Orschell CM and March KL: Peripheral blood 'endothelial progenitor cells' are derived from monocyte/macrophages and secrete angiogenic growth factors. Circulation 107: $1164-1169,2003$

26. Kalka C, Masuda H, Takahashi T, Kalka-Moll WM, Silver M, Kearney M, Li T, Isner JM and Asahara T: Transplantation of ex vivo expanded endothelial progenitor cells for therapeutic neovascularization. Proc Natl Acad Sci USA 97: 3422-3427, 2000.

27. James MF, Beauchamp RL, Manchanda N, Kazlauskas A and Ramesh V: A NHERF binding site links the betaPDGFR to the cytoskeleton and regulates cell spreading and migration. J Cell Sci 117: 2951-2961, 2004

28. Li WD, Hu N, Lei FR, Wei S, Rong JJ, Zhuang H and Li XQ: Autophagy inhibits endothelial progenitor cells migration via the regulation of MMP-2, MMP-9 and uPA under normoxia condition. Biochem Biophys Res Commun 466: 376-380, 2015.

29. Ji Y, Strawn TL, Grunz EA, Stevenson MJ, Lohman AW, Lawrence DA and Fay WP: Multifaceted role of plasminogen activator inhibitor-1 in regulating early remodeling of vein bypass grafts. Arterioscler Thromb Vasc Biol 31: 1781-1787, 2011.

30. Oku N, Sasabe E, Ueta E, Yamamoto T and Osaki T: Tight junction protein claudin-1 enhances the invasive activity of oral squamous cell carcinoma cells by promoting cleavage of laminin-5 gamma2 chain via matrix metalloproteinase (MMP)-2 and membrane-type MMP-1. Cancer Res 66: 5251-5257, 2006.

31. Li W, Tanaka K, Chiba Y, Kimura T, Morioka K, Uesaka T, Ihaya A, Sasaki M, Tsuda T and Yamada N: Role of MMPs and plasminogen activators in angiogenesis after transmyocardial laser revascularization in dogs. Am J Physiol Heart Circ Physiol 284: H23-H30, 2003.
32. Xu S, Zhu J, Yu L and Fu G: Endothelial progenitor cells: Current development of their paracrine factors in cardiovascular therapy. J Cardiovasc Pharmacol 59: 387-396, 2012.

33. Resch T, Pircher A, Kähler CM, Pratschke J and Hilbe W: Endothelial progenitor cells: Current issues on characterization and challenging clinical applications. Stem Cell Rev 8: 926-939, 2012.

34. Loomans CJ, de Koning EJ, Staal FJ, Rookmaaker MB, Verseyden C, de Boer HC, Verhaar MC, Braam B, Rabelink TJ and van Zonneveld AJ: Endothelial progenitor cell dysfunction: A novel concept in the pathogenesis of vascular complications of type 1 diabetes. Diabetes 53: 195-199, 2004.

35. Barthelmes D, Irhimeh MR, Gillies MC, Karimipour M, Zhou M, Zhu L and Shen WY: Diabetes impairs mobilization of mouse bone marrow-derived Lin(-)/VEGF-R2(+) progenitor cells. Blood Cells Mol Dis 51: 163-173, 2013.

36. Chen LL, Liao YF, Zeng TS, Yu F, Li HQ and Feng Y: Effects of metformin plus gliclazide compared with metformin alone on circulating endothelial progenitor cell in type 2 diabetic patients. Endocrine 38: 266-275, 2010

37. Esposito K, Maiorino MI, Di Palo C, Gicchino M, Petrizzo M, Bellastella G, Saccomanno F and Giugliano D: Effects of pioglitazone versus metformin on circulating endothelial microparticles and progenitor cells in patients with newly diagnosed type 2 diabetes - a randomized controlled trial. Diabetes Obes Metab 13: 439-445, 2011

38. Li X, Han Y, Pang W, Li C, Xie X, Shyy JY and Zhu Y: AMP-activated protein kinase promotes the differentiation of endothelial progenitor cells. Arterioscler Thromb Vasc Biol 28: $1789-1795,2008$

39. Yan Y, Tsukamoto O, Nakano A, Kato H, Kioka H, Ito N, Higo S, Yamazaki S, Shintani Y, Matsuoka K, et al: Augmented AMPK activity inhibits cell migration by phosphorylating the novel substrate Pdlim5. Nat Commun 6: 6137, 2015.

40. Park SY, Jung CH, Song B, Park OJ and Kim YM: Pro-apoptotic and migration-suppressing potential of EGCG, and the involvement of AMPK in the p53-mediated modulation of VEGF and MMP-9 expression. Oncol Lett 6: 1346-1350, 2013.

41. Lee GR, Jang SH, Kim CJ, Kim AR, Yoon DJ, Park NH and Han IS: Capsaicin suppresses the migration of cholangiocarcinoma cells by downregulating matrix metalloproteinase-9 expression via the AMPK-NF- $\kappa \mathrm{B}$ signaling pathway. Clin Exp Metastasis 31: 897-907, 2014

42. Visse R and Nagase H: Matrix metalloproteinases and tissue inhibitors of metalloproteinases: Structure, function, and biochemistry. Circ Res 92: 827-839, 2003.

43. Esfahanian N, Shakiba Y, Nikbin B, Soraya H, Maleki-Dizaji N, Ghazi-Khansari M and Garjani A: Effect of metformin on the proliferation, migration, and MMP-2 and -9 expression of human umbilical vein endothelial cells. Mol Med Rep 5: 1068-1074, 2012.

44. Hwang YP and Jeong HG: Metformin blocks migration and invasion of tumour cells by inhibition of matrix metalloproteinase- 9 activation through a calcium and protein kinase Calpha-dependent pathway: Phorbol-12-myristate-13-acetateinduced/extracellular signal-regulated kinase/activator protein-1. Br J Pharmacol 160: 1195-1211, 2010.

45. Fang Z, Xu X, Zhou Z, Xu Z and Liu Z: Effect of metformin on apoptosis, cell cycle arrest migration and invasion of A498 cells. Mol Med Rep 9: 2251-2256, 2014.

46. Yang N, Hui L, Wang Y, Yang H and Jiang X: SOX2 promotes the migration and invasion of laryngeal cancer cells by induction of MMP-2 via the PI3K/Akt/mTOR pathway. Oncol Rep 31: 2651-2659, 2014

47. Chen JS, Wang Q, Fu XH, Huang XH, Chen XL, Cao LQ, Chen LZ, Tan HX, Li W, Bi J, et al: Involvement of PI3K/PTEN/AKT/mTOR pathway in invasion and metastasis in hepatocellular carcinoma: Association with MMP-9. Hepatol Res 39: 177-186, 2009.

48. Tomic T, Botton T, Cerezo M, Robert G, Luciano F, Puissant A, Gounon P, Allegra M, Bertolotto C, Bereder JM, et al: Metformin inhibits melanoma development through autophagy and apoptosis mechanisms. Cell Death Dis 2: e199, 2011.

49. Kim YC and Guan KL: mTOR: A pharmacologic target for autophagy regulation. J Clin Invest 125: 25-32, 2015

50. Zhan Z, Xie X, Cao H, Zhou X, Zhang XD, Fan H and Liu Z: Autophagy facilitates TLR4- and TLR3-triggered migration and invasion of lung cancer cells through the promotion of TRAF6 ubiquitination. Autophagy 10: 257-268, 2014.

51. Tuloup-Minguez V, Hamaï A, Greffard A, Nicolas V, Codogno P and Botti J: Autophagy modulates cell migration and $\beta 1$ integrin membrane recycling. Cell Cycle 12: 3317-3328, 2013. 